Volume 14

\title{
The effect of parental residential school attendance and parental involvement on Indigenous youth's participation in sport and physical activity during school
}

Piotr Wilk, Dr.

Department of Epidemiology \& Biostatistics, Western University pwilk3@uwo.ca

Alana Maltby, Ms.

Department of Epidemiology \& Biostatistics, Western University alana.maltby@schulich.uwo.ca

\section{Martin Cooke, Dr.}

School of Public Health and Health Systems, University of Waterloo cooke@uwaterloo.ca

Janice Forsyth, Dr.

Department of Sociology, Western University

janice.forsyth@uwo.ca

\section{Follow the International Journal of Indigenous Health at: https://jps.library.utoronto.ca/index.php/ijih/index}

\section{Recommended Citation}

Wilk, P., Maltby, A., Cooke, M., \& Forsyth, J. (2019). The effect of parental residential school attendance and parental involvement on Indigenous youth's participation in sport and physical activity during school. International Journal of Indigenous Health, 14(2), 133-149. DOI 10.32799/ijih.v14i2.31929. 


\title{
The effect of parental residential school attendance and parental involvement on Indigenous youth's participation in sport and physical activity during school
}

\begin{abstract}
Introduction: The objective of this study was to assess the effect of parental residential school attendance on youth's participation in sport and physical activity (S/PA) at school and to explore the potential role that parental education and parental involvement in school activities may play in mediating this relationship. Methods: This cross-sectional study used the 2012 Aboriginal Peoples Survey and included youth ages 12-17 $(\mathrm{N}=4,840)$. Structural equation modeling techniques were used for models with observed and latent variables. Sampling weights and bootstrap weights were used for all analyses. Results: The results indicate $62.87 \%$ of youth participated in S/PA; $27.54 \%$ at school; $31.52 \%$ outside of school, and $40.94 \%$ in school and outside school. Mothers who attended residential schools had lower levels of educational attainment. Maternal education had a positive effect on parental involvement in school activities in dual parent households and parental involvement had a positive effect on S/PA. The indirect effects of residential school attendance on parental involvement and participation in S/PA were significant only for youth living with both parents and only for the effect of maternal residential school attendance. Maternal residential school attendance had a negative effect on parental involvement and on participation in S/PA. Discussion: The findings from this study indicate that interpersonal factors and historical contexts shape Indigenous youth's participation in S/PA.
\end{abstract}

\section{Keywords}

Sport, physical activity, Indigenous, youth, parents, Canada.

\section{Acknowledgements}

Data were provided by Statistics Canada through the Research Data Centres program and accessed under the Statistics Act of Canada. The analyses and the interpretation are the authors' alone. This research was supported by funding from the Children's Health Foundation

\section{Creative Commons License}

\section{(ब) $\Theta \Theta$}

This work is licensed under a Creative Commons Attribution-Noncommercial-No Derivative Works 4.0 License. 


\section{Glossary}

PA $=$ Physical activity

$\mathrm{S} / \mathrm{PA}=$ Sport and/or physical activity

PMK $=$ person most knowledgeable

\section{Introduction}

Indigenous populations in Canada comprise three distinct groups: First Nations, Métis, and Inuit. Indigenous peoples are the youngest and fastest growing segment of the Canadian population; in 2011, $28.0 \%$ were aged 14 and under compared to $16.5 \%$ of the total Canadian population (Statistics Canada, 2013). Participating in physical activity (PA) during leisure time has been found to be higher among Indigenous youth in Canada compared to their non-Indigenous counterparts (Findlay, 2011; Ng, Young, \& Corey, 2010). However, many Indigenous youth are still not meeting national and international recommendations of 60 mins/day of PA (Foulds, Warburton, \& Bredin, 2013; Young \& Katzmarzyk, 2007), and often have poorer health than non-Indigenous populations (Findlay, 2011).

Participation in PA during school hours may be especially important for Indigenous youth who face structural, institutional, and cultural barriers related to sport and/or PA (S/PA) outside of school (Forsyth, 2014; Halas, McRae, \& Carpenter, 2013; Mason \& Koehli, 2012). Opportunities for S/PA outside of school may also be limited due to misplaced and/or misidentified policy priorities for Indigenous PA development (Forsyth \& Heine, 2008), as well as other challenges, such as neighbourhood safety, transportation, and distance to recreational centres offering PA programmes (Kerpan \& Humbert, 2015).

$\mathrm{S} / \mathrm{PA}$ is influenced by a various of factors, including individual, interpersonal, environmental, and historical (Forsyth, 2007a; Smith, Findlay, \& Crompton, 2010; Wilk, Maltby, Cooke, \& Forsyth, 2018). For Indigenous children (6-14 years old) living out of community, factors related to participation in sport were found to be parental education, weekly contact with Elders, involvement in extracurricular activities, having very good to excellent health, higher income, and spending less than four hours per day watching TV or playing computer and videos games (K. Smith et al., 2010). Moreover, barriers related to historical factors such as colonization by Europeans, dispossession of traditional lands, and assimilative policies such as the residential school system have limited S/PA (Forsyth, 2007a, 2007b; Lavallée \& Lévesque, 2013; Richmond \& Ross, 2009; Willows, Hanley, \& Delormier, 2012). For instance, those who attended residential schools often did not have regular access to S/PA due to underfunding and lack of resources (Forsyth, 2013; Truth and Reconciliation Commission of Canada, 2015a). 
The consequences of residential schooling in Canada parallel experiences in the United States and Australia, where boarding or residential schools were also used as a form of assimilation (Archibald, 2006). In Canada, children were removed from their families and communities and were generally prohibited from speaking their languages or practicing their culture and spirituality (Miller, 1996). Yet, despite government attempts to assimilate Indigenous populations into the mainstream culture, it failed to separate Indigenous people from their identity (Truth and Reconciliation Commission of Canada, 2015b).

Children of residential school Survivors might be subjected to the same stressors as their parents, but also may encounter additional adversities as a result of living in households and communities affected by trauma (Bombay, Matheson, \& Anisman, 2014; Evans-Campbell, 2008). The pathways by which residential schools have impacted health and health behaviors of the Survivors and their children are not well understood due to the complexities of these effects (Kirmayer, Gone, \& Moses, 2014). Although there is still a need to uncover the relevant individual and interpersonal predictors of participation in S/PA, it is equally important to assess the mechanisms by which colonial practices affect S/PA (Forsyth, 2007b). These practices may not only affect levels of participation in S/PA, but may also shape proximal factors, such as socio-economic resources and parenting skills that have been found to be related to this health behavior (Loppie Reading \& Wien, 2009). Currently, there is a lack of such research.

Parents who attended residential schools may have difficulty making appropriate decisions regarding healthy eating and PA for their children because of the trauma they experienced at school (Willows et al., 2012). Distrust and tension as a result of the residential school system and legacies of racial discrimination may have generated barriers for Indigenous parents to develop a connection with schools, impeding their ability to become involved in and have a positive attitude towards schooling and educators (Milne, 2016). Therefore, Indigenous parents who attended residential schools may be less likely to provide their children with adequate support in school related activities because of their own experiences with the educational system.

The relationship between residential school attendance and parenting behaviors is complex and involves other factors. The personal experiences of residential school Survivors, for instance, differs from person to person and attendees will have had different levels of resilience and community support in overcoming the traumatic experiences they endured (Aguiar \& Halseth, 2015). Educational has been found to be a protective factor contributing to resilience among those who have attended residential schools (Nichol, 2000). The role of educational attainment and the mechanism through which it may affect the relationship between residential school attendance and parental involvement in school activities, however, has not been explored in the past research. To address this gap, we hypothesize that 
educational attainment mediates the relationship between residential school attendance and parental participation in school activities.

Social support has been found to be positively related to youths' PA, with greater parental support being conducive to increased levels of PA (Biddle, Atkin, Cavill, \& Foster, 2011; Yao \& Rhodes, 2015). Given the consistent findings in the literature related to the effect of parental support on PA, we hypothesize that youth whose parents are more involved in school activities are expected to participate more frequently in S/PA in school, compared to youth whose parents are less likely to be involved.

Finally, boys attending residential schools were encouraged to participate in organized sport more than girls (Forsyth, 2007a). Previous research has suggested that parental modelling of PA is influential on youth's PA (Gustafson \& Rhodes, 2006; Yao \& Rhodes, 2015). As boys were provided with more opportunities than girls to participate in organized sport at residential schools, it is postulated that there may be an intergenerational relationship between fathers' S/PA behaviors and that of their children.

The objective of this study was to assess how parental residential school attendance affects youth's participation in S/PA at school and to explore the potential role that parental education and parental involvement in school activities may play in mediating this relationship. To this end, our overall hypothesis is that parental residential school attendance has a negative indirect effect on youth's participation in S/PA at school. Figure 1 depicts the theoretical model that represents this overall hypothesis and its specific components. 


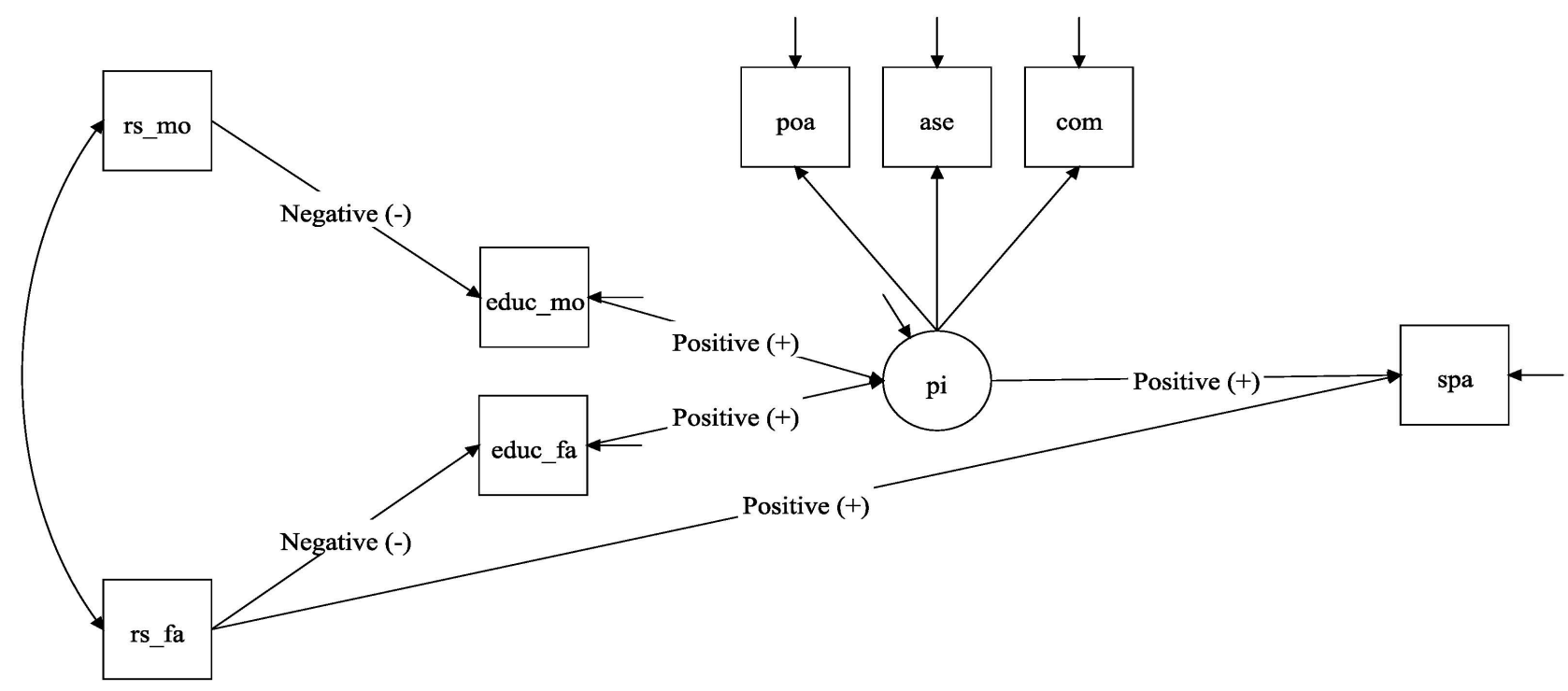

Figure 1. The theoretical model to be tested and its specific components.

Note: $\mathrm{RS}=$ residential school; $\mathrm{MO}=$ mother; $\mathrm{FA}=$ father; educ $=$ educational attainment; $\mathrm{PI}=$ parental involvement; SPA = sport and physical activity; poa = "Participated in other school activities"; ase = "Attended school event in which respondent participated"; com = "Spoke to, corresponded, or visited teacher".

\section{Methods}

\section{Study Design and Data}

This study employed a cross-sectional design using the 2012 Aboriginal Peoples Survey (Statistics Canada, 2012). The 2012 APS is a large cross-sectional $(\mathrm{N}=28,410)$, nationally representative survey of Indigenous people living off-reserve (Statistics Canada, 2012). The current study was limited to the APS respondents who were between the age of 12 and 17 at the time of the interview, and who attended elementary or high school (grades 7 to $12 ; \mathrm{N}=4,840$ ). Proxy reporting, primarily from parents and caregivers (person most knowledgeable [PMKs]), was used for most of youth aged 12 to 14 years and almost half of youth aged 15 to 17 years (Statistics Canada, 2012). 


\section{Measurement Instruments}

Participation in sport and/or physical activities (spa). Respondents (or PMKs) were asked three questions related to their participation in S/PA: 1) "At any time during this school year, did you (or your child) participate in a sport or a physical activity or played organized sport (including taking lessons);" 2) "Were they organized by your school, outside the school, or both?"; 3) "How often did you usually participate in any of these activities?" For youth who replied positively to the first question and who indicated in the second question that they participated in these activities at schools, level of participation is S/PA at school was measured on a three-point scale: 1) Less than once per week, 2) 1-3 times per week, and 3 ) 4 or more times per week. Youth who indicated that they did not participate in S/PA at school were given a score of zero. In the statistical models, the level of participation in S/PA (outcome variable) was represented as a latent variable with a single categorical indicator.

Parental residential school attendance (rs_mo and rs_fa). Respondents were asked whether or not their mothers and fathers attended residential schools. For younger children, or those responding by proxies, PMKs were asked these questions directly. Two binary variables indicating whether or not the child's mother or father attended residential school were created.

Parental involvement in school activities (pi). Respondents were asked whether or not, during the current school year, their parents: 1) "Spoke to, corresponded, or visited teacher"; 2) "Attended school event in which respondent participated"; and 3) "Participated in other school activities". A latent variable with the three survey instruments serving as its binary indicators was used to assess parental involvement in school activities.

Parental educational attainment (educ_mo and educ_fa). Respondents were asked to indicate the level of education for their mothers and fathers which was then measured on a ten-point scale, ranging from (1) "No schooling" to (10) "University certificate diploma or degree above bachelor's level".

\section{Statistical Analysis}

First, descriptive statistics were computed for the variables used in this study. Then, to assess the fit of the proposed model, structural equation modeling (SEM) techniques were used, for models with observed and latent variables. SEM estimates the relationships between the latent variables and their indicators in the measurement model and, at the same time, the direct and indirect effects among the latent and observed variables in the structural model. SEM techniques were used to test the role of educational attainment and parental involvement in school activities as two mediators of the relationship between residential school attendance and S/PA at school. 
Respondents (or PMKs) were asked about their household structure and, based on their responses, we categorized them into three groups: 1) youth living with both parents $[n=2,340]$; $)$ youth living in single parent households headed by mothers $[n=1,640]$; and 3) youth living in single parent households headed by fathers [ $n=490]$. For the remaining 380 youth, information of their household structure was not available. To accommodate these differences in household structures and to consider their potential effects on all the relationships in the proposed model, we tested the hypothesised model separately for youth in each group. Thus, for youth living in single parent households headed by mothers, we assessed only the effect of maternal residential school attendance and educational attainment on parental involvement and participation in S/PA, as the data on paternal characteristics were not applicable. The opposite model structure was imposed on a sample of youth living in single parent households headed by fathers.

The weighted least squares means and variance adjusted estimator with delta parametrization was used for data analysis. A metric from one of the indicators (the reference indicator) was assigned to the latent variable measuring parental involvement. Sampling weights and 1,000 bootstrap weights were used for all analyses to account for sampling design effects. A Fay adjustment factor of 0.75 was applied while using the bootstrap method (Budinski \& Langlet, 2015). The model fit was assessed based on four model fit indices: chi-square, CFI, TLI, and RMSEA. All models were tested first without bootstrap weights to assess model fit and then with bootstrap weights to obtain correct standard errors (models with bootstrap weights do not produce model fit statistics except for RMSEA). The significance level for all parameter estimates was $\mathrm{p}<0.05$. Missing data were handled by first estimating the hypothesized models using a listwise deletion method and then using the full-information estimation approach (FIML). These two estimation approaches yielded almost identical estimates in both magnitude of effects and level of significance; therefore, only the results of the FIML are reported. Mplus 7.14 was used for all analyses (Muthén \& Muthén, 1998-2015).

\section{Results}

\section{Descriptive Statistics}

Among youth $($ mean age $=15.19), 62.87 \%$ participated in S/PA: $27.54 \%$ participated only at school; $31.52 \%$ only outside school, and $40.94 \%$ participated in both. For youth who participated at school, 6.35\% indicated that they participate less than once per week, 60.85\% participated 1 to 3 times per week, and $32.80 \%$ participated 4 or more times per week. Among this sample, $50.44 \%$ identified as First Nations; 43.27\% Métis; 5.61\% Inuit, and 0.67\% reported multiple Indigenous identities.

Of the 4,470 youth, 5.66\% and $6.49 \%$ indicated that their mothers and fathers, respectively, attended residential schools. The majority of mothers $(63.93 \%)$ and less than half of fathers $(47.76 \%)$ 
reported having some postsecondary education. In terms of parental involvement: $78.77 \%$ "Spoke to, corresponded or visited teacher", 59.66\% "Attended school event in which respondent participated", and 42.06\% "Participated in other school activities".

\section{Model Fit}

The hypothesized model (Figure 1) tested the effect of parental residential school attendance on youth's S/PA at school and was tested separately for youth living with both parents, with mothers only, and with fathers only. For all three models, the goodness of fit statistics met the criteria for an adequate model fit (see Table 1) and there were no significant modification indices suggesting that additional pathways should be added to the model in any of the three groups. The factor loadings for the latent variable representing parental involvement are reported in Table 2 (section Measurement Model). Factor loadings for the three indicators were statistically significant with the standardized factor loading between (0.386 and 0.930$)$.

Table 1. Goodness of fit statistics

\begin{tabular}{lrrr}
\hline Model Fit: & $\begin{array}{r}\text { Both Parents } \\
\mathbf{n = 2 , 1 2 0}\end{array}$ & $\begin{array}{r}\text { Lone Mothers } \\
\mathbf{n = 1 , 8 4 0}\end{array}$ & $\begin{array}{r}\text { Lone Fathers } \\
\mathbf{n}=\mathbf{5 0 0}\end{array}$ \\
\hline MODEL & & & \\
Chi-Square (df/p-value) & $22.288(17 / 0.1739)$ & $7.581(9 / 0.5769)$ & $11.493(8 / 0.1753)$ \\
RMSEA (90\% CI) & $0.012(0.000-0.023)$ & $0.000(0.000-0.025)$ & $0.031(0.000-0.068)$ \\
CFI & 0.990 & 1.000 & 0.967 \\
TLI & 0.983 & 1.011 & 0.938 \\
\hline
\end{tabular}

Table 2. Direct and indirect effects among the latent and observed variables

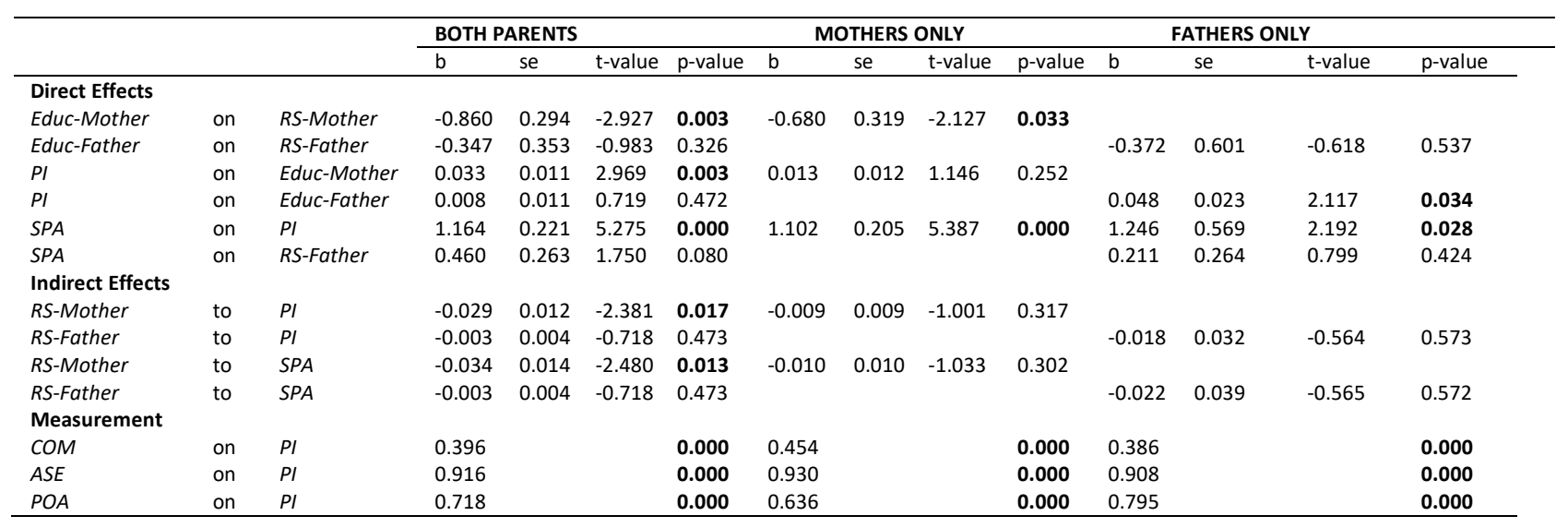


Notes: RS = residential school; PI = parental involvement; SPA = sport and physical activity; poa $=$ "Participated in other school activities"; ase = "Attended school event in which respondent participated"; com $=$ "Spoke to, corresponded, or visited teacher"

Bolded values are statistically significant

\section{Hypotheses Testing}

The results of the hypothesis testing are presented in Table 2. In terms of Hypothesis \#1, the results for a sample of youth living with both parents and for a sample of youth living with mothers suggest that mothers who attended residential schools were found to have lower levels of education $(b=$ -0.860 and -0.680 , respectively). However, the effect of father's residential school attendance on their educational attainment was statistically not significant for youth living with both parents or living only with fathers. The results for Hypothesis \#2 suggest that maternal education has a significant positive effect on parental involvement in school activities $(b=0.033)$, but only in the subsample of youth living with both parents. The effect of paternal education on parental involvement was statistically significant only in the subsample of youth living with fathers $(b=0.048)$, but not in households with both parents. As predicted (Hypothesis \#3), parental involvement in school activities had a significant, positive, and relatively consistent effect on participation in S/PA at school in all three subsamples, that is, for youth living with both parents, only with mothers, and only with fathers $(b=1.164,1.102,1.246$, respectively). Finally, in terms of Hypothesis \#4, we found that paternal residential school attendance did not have a statistically significant effect on participation in S/PA at schools for youth living with both parents and for those living only with their fathers.

The proposed model also tested the indirect effects of residential school attendance on parental involvement in school activities (Hypothesis \#5) and on youth's participation in S/PA at school (Hypothesis \#6). These two indirect effects were statistically significant only in the subsample of youth living with both parents and only for the effect of maternal, but not paternal, residential school attendance. Specifically, maternal residential school attendance was found to have a significant negative effect on parental involvement in school activities $(b=-0.029)$ and on youths' participation in S/PA at school $(b=-0.034)$.

\section{Limitations}

This study is not without limitations. Notably, the study employs a cross-sectional design and therefore cannot infer any causal relationships. Also, due to limited questions pertaining to participation in S/PA within the APS survey, we were not capable of adequately determining the PA levels of the youth who participated. Moreover, the survey may not capture all activities that are considered S/PA among Indigenous youth. Lastly, participation in S/PA was self or proxy reported, which may result in 
reporting bias (LeBlanc \& Janssen, 2010). Regardless, this study provides valuable insight into factors related to Indigenous youth's participation in S/PA at school.

\section{Discussion}

Parents play an important role in the development of their children's health behaviors. For Indigenous youth, parental support has been found to be an important predictor of PA (Biddle et al., 2011; Wilk et al., 2018; Yao \& Rhodes, 2015). A recent review by McHugh et al. (2018) on the sport and recreation experiences of Indigenous youth indicates that relationships with other community members and family could enhance experiences in sport in recreation through supportive behaviors such as encouragement, role modeling, financial support, and transportation to sport and recreation opportunities. The findings from the current study confirm the positive relationships between social support and PA behaviors. Parental involvement in their children's school activities was found to be significantly associated with youth's participation in S/PA, indicating that Indigenous youth whose parents are more actively involved at school are more likely to engage in school-based S/PA. Importantly, regardless of household structure (e.g., dual parent households, mothers only, and fathers only), the magnitude of the relationship between parental involvement and participation in S/PA was consistent across all three groups. Thus, in order to increase the active behaviors of youth, focus should be placed on the involvement of parents and the provision of social support.

Although the majority of parents in this study reported being involved in their children's school activities, research examining family and school relations has indicated that Indigenous families are posed with distinct challenges when connecting and being involved with schools (Milne, 2016). Due to the legacies of discrimination in schooling, parents are less likely to be involved and there is less parentteacher communication (Milne, 2016). Rather than put the blame on parents, it is necessary to determine barriers and facilitators related to parent involvement in school activities and youth's participation in $\mathrm{S} / \mathrm{PA}$.

For youth living with both parents, maternal residential school attendance has an indirect negative effect on youth's participation in S/PA at school and its effect is mediated by parental education and parental involvement in school activities. Given that schooling was the dominant method of assimilation into Euro-Canadian ways of life, it has led to a "deep-rooted distrust" in the educational system among Indigenous people (Milne, 2016, p. 276). In support of this argument, we found a negative relationship between the mother's residential school attendance and educational attainment for youth living with both parents, and in lone parent households. In turn, maternal education was found to be positively associated with parental involvement, but only in a sample of youth living with both parents. Also, an indirect effect was found between the mother's residential attendance (in dual parent 
households) and youth's participation in S/PA. This finding indicates that youth whose mothers attended residential school tend to participate less in S/PA at school.

As the role of educational attainment and the pathways through which it affects the relationship between residential school attendance and parental involvement in school activities has not been previously explored. Despite this, a few studies have suggested education can be a way of coping or act as a protective factor. In a study of six First Nations individuals identified as "successful" residential school Survivors, Nichol (2000) found that their resilience could be linked to protective factors including, a happy and nurturing early childhood, high intelligence, life-long interest in education, cooperative values, long-term marriage, and strong spiritual beliefs. Furthermore, attaining further education has become an important way of healing or coping for many Survivors and allows them to reclaim what was denied to them as children (Dion Stout \& Kipling, 2003). In this context, it is possible that educational attainment could be a proxy for resiliency.

Contradicting our hypothesis, for fathers, we found that residential school attendance did not have an indirect effect on parental involvement in school activities or on participation in S/PA. There was also no evidence for the direct effect of residential school attendance on youth's participation in $\mathrm{S} / \mathrm{PA}$. Yet, evidence has indicated that in residential schools boys were encouraged to be active and participate in organized sport more than girls (Forsyth, 2007a, 2007b). Although all the observed effects were in the expected directions, none of them were statistically significant, except for the positive effect of educational attainment on parental involvement in lone father households, but not in dual parent households.

With the exception of significant relationships between paternal involvement and youth's participation in S/PA and paternal education and parental involvement, all other relationships were found to be non-significant for fathers. There are a few potential explanations for these results. First, the relatively small sample size of fathers in this study may have impacted the statistical power needed to obtain significant results. Also, the model may not include other important factors that influence parental involvement and, as such, more work is needed to determine these factors and test the model. Yet, the results presented in this study could lend some support to the idea of education being a protective factor or coping method (Dion Stout \& Kipling, 2003; Nichol, 2000).

\section{Conclusions}

As PA, particularly sport, is critical in youth's positive development (Bruner et al., 2016), there is a need to better understand the experiences of Indigenous youth in relation to S/PA in various settings and how these experiences can be influenced by various ecological factors (i.e., intrapersonal, interpersonal, organizational, community, policy/systems/environments) (McHugh et al., 2018). Our 
findings in the current study suggest that the influence of residential schools on parental involvement requires further exploration to clarify this relationship. To develop effective policies, there is a need to study the interrelationships between distal and more proximal factors to determine how they impact S/PA (B. J. Smith et al., 2010), especially among Indigenous youth, where limited research is available. There is an urgent concomitant need to develop policies at the federal, provincial, and territorial level that connect relevant departments to address the multitude of factors at the community level, including in the schools. The absence of structured decision-making models for governments, the non-profit sector, and non-governmental organizations involved in Indigenous health and S/PA, leaves room for misunderstanding of what is really happening in the wake of the residential school system. 


\section{References}

Aguiar, W., \& Halseth, R. (2015). Aboriginal Peoples and Historic Trauma: The Processes of Intergenerational Transmission. Retrieved from Prince George, BC, CAN: http://site.ebrary.com/lib/uwo/docDetail.action?docID=11082023

Archibald, L. (2006). Decolonization and Healing: Indigenous Experiences in the United States, Australia and Greenland. Retrieved from Ottawa, ON:

Biddle, S. J. H., Atkin, A. J., Cavill, N., \& Foster, C. (2011). Correlates of physical activity in youth: A review of quantitative systematic reviews. International Review of Sport and Exercise Psychology, 4(1), 25-49. doi:10.1080/1750984X.2010.548528

Bombay, A., Matheson, K., \& Anisman, H. (2014). The intergenerational effects of Indian Residential Schools: Implications for the concept of historical trauma. Transcultural Psychiatry, 51(3), 320338. doi: $10.1177 / 1363461513503380$

Bruner, M. W., Hillier, S., Baillie, C. P. T., Lavallee, L. F., Bruner, B. G., Hare, K., . . Lévesque, L. (2016). Positive youth development in Aboriginal physical activity and sport: A systematic review. Adolescent Research Review, 1(3), 257-269. doi:10.1007/s40894-015-0021-9

Budinski, R., \& Langlet, É. (2015). Aboriginal Peoples Survey, 2012: User's Guide to the Public Use Microdata File (PUMF). Retrieved from: http://sda.chass.utoronto.ca/sdaweb/dli2/aps/aps2012/more_doc/APS2012ENgid.pdf

Dion Stout, M., \& Kipling, G. (2003). Aboriginal People, Resilience and the Residential School Legacy. Ottawa, ON. Retrieved from: http://www.ahf.ca/downloads/resilience.pdf

Evans-Campbell, T. (2008). Historical trauma in American Indian/Native Alaska communities: A multilevel framework for exploring impacts on individuals, families, and communities. Journal of Interpersonal Violence, 23(3), 316-338. doi:10.1177/0886260507312290

Findlay, L. C. (2011). Physical activity among First Nations people off reserve, Métis and Inuit. Health Rep, 22(1), 47-54. Retrieved from:

http://ovidsp.ovid.com/ovidweb.cgi?T $=\mathrm{JS} \& \mathrm{CSC}=\mathrm{Y} \& \mathrm{NEWS}=\mathrm{N} \& \mathrm{PAGE}=$ fulltext\&D $=$ med5 $\& A N=$ 21510589.

Forsyth, J. (2007a). Aboriginal Leisure in Canada. In R. McCarville \& K. MacKay (Eds.), Leisure for Canadians (pp. 163-170). State College, PA: Venture Publishing Inc. 
Forsyth, J. (2007b). The Indian Act and the (re)shaping of Canadian Aboriginal sport practices. International Journal of Canadian Studies, 35, 95-111. doi: 10.7202/040765ar

Forsyth, J. (2013). Bodies of meaning: Sports and games at Canadian residential schools. In J. Forsyth \& A. R. Giles (Eds.), Aboriginal Peoples and Sport in Canada: Historical Foundations and Contemporary Issues (pp. 182-205). Vancouver, BC: UBC Press.

Forsyth, J. (2014). Aboriginal sport in the city: Implications for participation, health, and policy in Canada. Aboriginal Policy Studies, 3(1\&2), 214-222. doi:10.5663/aps.v3il-2.21707

Forsyth, J., \& Heine, M. (2008). Sites of meaning, meaningful sites? Sport and recreation for Aboriginal youth in inner city Winnipeg, Manitoba. Native Studies Review, 17(2), 1-16.

Foulds, H. J. A., Warburton, D. E. R., \& Bredin, S. S. D. (2013). A systematic review of physical activity levels in Native American populations in Canada and the United States in the last 50 years. Obesity Reviews, 14(7), 593-603. doi:10.1111/obr.12032

Gustafson, S. L., \& Rhodes, R. E. (2006). Parental correlates of physical activity in children and early adolescents. Sports Medicine, 36(1), 79-97. doi:10.2165/00007256-200636010-00006

Halas, J., McRae, H., \& Carpenter, A. (2013). The quality and cultural relevance of physical education for Aboriginal youth. In J. Forsyth \& A. R. Giles (Eds.), Aboriginal Peoples and Sport in Canada: Historical Foundations and Contemporary Issues (pp. 182-205). Vancouver, BC: UBC Press.

Kerpan, S., \& Humbert, L. (2015). Playing together: The physical activity beliefs and behaviors of urban Aboriginal youth. Journal of Physical Activity and Health, 12(10), 1409-1413. doi:10.1123/jpah.2014-0533

Kirmayer, L. J., Gone, J. P., \& Moses, J. (2014). Rethinking Historical Trauma. Transcultural Psychiatry, 51(3), 299-319. doi:10.1177/1363461514536358

Lavallée, L., \& Lévesque, L. (2013). Two-eyed seeing: Physical activity, sport, recreation promotion in Indigenous communities In J. Forsyth \& A. R. Giles (Eds.), Aboriginal Peoples and Sport in Canada: Historical Foundations and Contemporary Issues (pp. 206-228). Vancouver, BC: UBC Press

LeBlanc, A. G. W., \& Janssen, I. (2010). Difference between self-reported and accelerometer measured moderate-to-vigorous physical activity in youth. Pediatric Exercise Science, 22(4), 523-534. doi:10.1123/pes.22.4.523 
Reading, C.L. \& Wien, F. (2009). Health Inequalities and Social Determinants of Aboriginal Peoples' Health. Prince George, BC: National Collaborating Centre for Aboriginal Health. Retrieved from: http://www.nccahccnsa.ca/Publications/Lists/Publications/Attachments/46/health_inequalities_EN_web.pdf

Mason, C., \& Koehli, J. (2012). Barriers to physical activity for Aboriginal youth: Implications for community health, policy, and culture. Pimatisiwin: A Journal of Aboriginal and Indigenous Community Health, 10(1), 97-108. Retrieved from: http://www.pimatisiwin.com/online/wpcontent/uploads/2012/07/08MasonNew.pdf.

McHugh, T. F., Deal, C. J., Blye, C. J., Dimler, A. J., Halpenny, E. A., Sivak, A., \& Holt, N. L. (2018). A Meta-Study of Qualitative Research Examining Sport and Recreation Experiences of Indigenous Youth. Qualitative Health Research. doi:10.1177/1049732318759668

Miller, J. R. (1996). Shingwauk's Vision: A History of Native Residential Schools. Toronto, ON: University of Toronto Press.

Milne, E. (2016). "I Have the Worst Fear of Teachers": Moments of inclusion and exclusion in family/school relationships among Indigenous families in Southern Ontario. Canadian Review of Sociology, 53(3), 270-289. doi:10.1111/cars.12109

Muthén, L. K., \& Muthén, B. O. (1998-2015). Mplus User's Guide. Eighth Edition. Los Angeles, CA: Muthén \& Muthén. Retrieved from: https://www.statmodel.com/download/usersguide/MplusUserGuideVer_8.pdf

Ng, C., Young, T. K., \& Corey, P. N. (2010). Associations of television viewing, physical activity and dietary behaviours with obesity in Aboriginal and non-Aboriginal Canadian youth. Public Health Nutrition, 13(9), 1430-1437. Retrieved from http://ovidsp.ovid.com/ovidweb.cgi?T $=\mathrm{JS} \& \mathrm{CSC}=\mathrm{Y} \& \mathrm{NEWS}=\mathrm{N} \& \mathrm{PAGE}=$ fulltext\&D=med5\&AN= 20441661

Nichol, R. A. (2000). Factors contributing to resilience in Aboriginal persons who attended residential schools. (Master of Social Work), University of Manitoba, Manitoba. Retrieved from: http://hdl.handle.net/1993/2331

Richmond, C. A., \& Ross, N. A. (2009). The determinants of First Nation and Inuit health: A critical population health approach. Health \& Place, 15(2), 403-411.

doi:10.1016/j.healthplace.2008.07.004 
Smith, B. J., Grunseit, A., Hardy, L. L., King, L., Wolfenden, L., \& Milat, A. (2010). Parental influences on child physical activity and screen viewing time: a population based study. BMC Public Health, 10(1), 593. doi:10.1186/1471-2458-10-593

Smith, K., Findlay, L., \& Crompton, S. (2010). Participation in sports and cultural activities among Aboriginal children and youth. Canadian Social Trends, 90. Retrived from: https://www150.statcan.gc.ca/n1/pub/11-008-x/2010002/article/11286-eng.htm

Statistics Canada. (2012, January 31 2012). Aboriginal Peoples Survey (APS). Retrieved from http://www23.statcan.gc.ca/imdb/p2SV.pl?Function=getSurvey\&SDDS=3250

Statistics Canada. (2013). Aboriginal Peoples in Canada: First Nations People, Métis and Inuit. 1-23. Retrieved from: http://www12.statcan.gc.ca/nhs-enm/2011/as-sa/99-011-x/99-011-x2011001eng.pdf

Truth and Reconciliation Commission of Canada. (2015a). Honouring the Truth, Reconciling for the Future: Summary of the Final Report of the Truth and Reconciliation Commission of Canada. Retrieved from:

http://www.trc.ca/assets/pdf/Honouring_the_Truth_Reconciling_for_the_Future_July_23_2015.pd $\mathrm{f}$

Truth and Reconciliation Commission of Canada. (2015b). What we have learned: Principles of truth and reconciliation. Retrieved from http://nctr.ca/assets/reports/Final\%20Reports/Principles_English_Web.pdf

Wilk, P., Maltby, A., Cooke, M., \& Forsyth, J. (2018). Correlates of participation in sports and physical activities among Indigenous youth. Aboriginal Policy Studies, 7(1), 62-83. doi:10.5663/aps.v7i1.28563

Willows, N. D., Hanley, A. J., \& Delormier, T. (2012). A socioecological framework to understand weight-related issues in Aboriginal children in Canada. Applied Physiology, Nutrition, and Metabolism, 37(1), 1-13. doi:10.1139/h11-128

Yao, C. A., \& Rhodes, R. E. (2015). Parental correlates in child and adolescent physical activity: A meta-analysis. International Journal of Behavioral Nutrition \& Physical Activity, 12(1), 10-10. doi:10.1186/s12966-015-0163-y

Young, T. K., \& Katzmarzyk, P. T. (2007). Physical activity of Aboriginal people in Canada. Applied Physiology, Nutrition, and Metabolism, 32(S2E), S148-S160. doi:10.1139/h07-110. 